\title{
SUB-CLINICAL ATHEROSCLEROSIS IN HYPERTENSION.
}

1. MCPS, FCPS

Professor Medicine

United Medical and Dental College, Karachi.

2. FCPS

Associate Professor Medicine Rawal Institute of Health Sciences, Islamabad.

3. FCPS

Assistant Professor Medicine United Medical and Dental College, Karachi.

Correspondence Address:

Dr. Farhat Bashir

40-B, $1^{\text {st }}$ East Street, Phase 1, DHA Karachi.

drfarhatbashir@gmail.com

Article received on: 31/08/2019

Accepted for publication:

$11 / 11 / 2019$
Farhat Bashir ${ }^{1}$, Nadia Shams ${ }^{2}$, Ayesha Nageen ${ }^{3}$

ABSTRACT... Objectives: In the presence of the rising incidence of cardiovascular disease in the developing world, it is imperative to focus on prevention. Many cardio-metabolic risk factors are responsible for development of atherosclerosis in hypertensive patients. It is important to know which factors contribute the most to this condition. Study Design: Cross Sectional study. Setting: Departments of Medicine and Radiology at Creek General Hospital, United Medical and Dental College, Karachi. Period: June 2015 to June 2016. Material \& Methods: A cross sectional study was planned and the subjects were selected by consecutive sampling. Physical examination data and laboratory reports were obtained. All the subjects underwent Carotid Doppler studies. The data as analyzed on SPSS ver.20.0. Relationship of the variables to CIMT was ascertained by Pearson's Correlation in both hypertensive and non-hypertensive subjects. P-value of $<0.05$ was considered significant. Results: All the variables like age, BMl, glycemic indices and the different fractions of the lipid profile were significantly higher in hypertensive patients. CIMT was significantly higher in hypertensive patients. The studied cardiometabolic variables were related to CIMT in both groups of patients but these variables were related more strongly in subjects without hypertension confirming the assumption that hypertension plays a major role in atherosclerosis. Conclusion: Hypertension is one of the most potent modifiable risk factors contributing to atherosclerosis.

Key words: $\quad$ CIMT, Cardio-Metabolic, Hypertension.

Article Citation: Bashir F, Shams N, Nageen A. Sub-clinical atherosclerosis in hypertension. Professional Med J 2020; 27(10):2093-2098.

DOI: 10.29309/TPMJ/2020.27.10.4095

\section{INTRODUCTION}

Carotid Doppler studies are used to assess both clinical and sub-clinical atherosclerosis by measuring carotid intima media thickness (CIMT), carotid plaques and carotid stenosis. These studies have been used as a supplement to Framingham risk score to improve the categorization of cardiovascular risk. ${ }^{1}$ CIMT is an independent predictor of cardiovascular mortality and morbidity. ${ }^{2}$ The convenience and ease of use, combined with the prediction capacity for subsequent coronary artery disease and stroke has made it a commonly employed clinical and research tool. ${ }^{3}$ Measurement of CIMT has enabled clinicians to decide about the feasibility of using aggressive treatment for primary and secondary prevention of atherosclerotic diseases. It has also been used to assess response to therapy and demonstrate regression of CIMT. ${ }^{4,5}$
Cardiovascular disease is associated with multiple risk factors, both modifiable and non-modifiable. Hypertension is an important modifiable risk factor. Many prospective epidemiological studies have shown a strong correlation of hypertension with coronary artery disease, heart failure, cerebrovascularaccidents and peripheralvascular disease. ${ }^{6}$ Primary prevention plays an important part in reducing the prevalence and incidence of cerebrovascular mortality. This fact is supported by evidence that management of hypertension improved cardiovascular health. ${ }^{7}$ Hypertension contributes to cardiovascular disease through atherosclerosis. Atherosclerosis can be assessed non-invasively by carotid doppler studies. Because of an epidemic rise of cerebrovascular diseases in South Asia the impact of hypertension and other risk factors, on atherosclerosis needs to be estimated in this population. Atherosclerosis is the pathophysiological process leading 
to cardiovascular disease. Measurement of atherosclerosis by non-invasive carotid Doppler studies allows us to diagnose the presence and extent of atherosclerosis and its' response to management. All risk factors for cardiovascular disease lead to atherosclerosis. If we could identify the role played by different factors it would allow us to focus on management of the conditions which have maximal effect on atherosclerosis. Thus both primary and secondary prevention of cardiovascular disease will be optimized.

The purpose of our study was to evaluate the prevalence of increased CIMT in hypertensive patients, and to assess the impact of different cardio-metabolic risk factors on CIMT in these patients.

\section{MATERIAL \& METHODS}

This was a cross-sectional descriptive study conducted in the Departments of Medicine and Radiology at Creek General Hospital, United Medical and Dental College, Karachi. We included 66 hypertensive patients with 67 non-hypertensive controls in the study. Patients with acute illness and known coronary artery disease, congestive cardiac failure, cerebrovascular accident or peripheral artery disease were excluded.

The study was conducted over a period of one year from June 2015 to June 2016. After approval by the Ethical Review Committee of the institution, a proforma was filled for every patient. The data included patient details regarding anthropometric measurements, clinical data and laboratory investigations. The variables included age, gender, BMI, smoking, blood pressure both systolic and diastolic, blood glucose levels and fasting lipid profile. All patients underwent carotid Doppler studies by a single operator using a Toshiba Nemio 35 in B-mode with a 15 $\mathrm{Hz}$ transducer. The CIMT was measured as the distance between the lumen and intima interface; and the media and adventitia junction at the far wall of both common carotid arteries and their mean was taken as CIMT.

SPSS 20.0 was used for analysis of the data. Categorical variables were described using mean and percentage and they were compared using Chi square test. Continuous variables were described as mean and standard deviation and t-test was used to compare these variables. Pearson correlation was used to examine the role of different cardio-metabolic risk factors on CIMT in both the hypertensive and control populations. P-value of $<0.05$ was considered significant.

\section{RESULTS}

The study population included 66 hypertensive patients and 67 non-hypertensive subjects. There were 42 male and 91 female subjects. The mean age of the hypertensive cohort was $49.7 \pm 12.6$ while that of the non-hypertensive population was $41.4 \pm 17.5$ years. This age difference was statistically significant. Weight and BMl was also significantly higher in hypertensive patients. (Table-I) All the fractions of the lipid profile and the indicators of glycemic control were also significantly high in hypertensive patients. Carotid intima media thickness was significantly higher in hypertensive patients.

The Pearson's correlation showed that although age, BMI, systolic and diastolic blood pressure, fasting and random blood glucose levels, total cholesterol, LDL cholesterol and triglycerides were all associated with CIMT in both hypertensive and non-hypertensive subjects; they were more strongly related to CIMT in non-hypertensive patients as compared to the hypertensive subjects. (Table-II) CIMT was greater in hypertensive patients (Table-I), therefore it is deduced that hypertension has the greatest impact on subclinical atherosclerosis in this cohort.

\section{DISCUSSION}

The main objective of the study was to assess the role played by different cardio-metabolic risk factors towards atherosclerosis in hypertensive patients. The factors usually associated with atherosclerosis such as BMI, systolic blood pressure, diastolic blood pressure, fasting and random blood glucose, total cholesterol, LDL cholesterol, HDL cholesterol were found to be significantly associated with hypertensive subjects as compared to subjects with normal blood pressures. 


\begin{tabular}{|c|c|c|c|c|c|}
\hline \multicolumn{2}{|c|}{ Variables } & $\begin{array}{l}\text { Total Population } \\
\qquad N=133\end{array}$ & $\begin{array}{c}\text { Patients with } \\
\text { Hypertension (cases) } \\
\mathrm{N}=66(49.6 \%)\end{array}$ & $\begin{array}{c}\text { Patients without } \\
\text { Hypertension (controls) } \\
\mathrm{N}=67(50.4 \%)\end{array}$ & P-Value \\
\hline \multicolumn{2}{|c|}{ AGE (years) } & $45.5 \pm 15.7$ & $49.7 \pm 12.6$ & $41.4 \pm 17.5$ & $0.000 \#$ \\
\hline \multirow{2}{*}{ Gender } & Male & $42(31.6 \%)$ & $24(36.4 \%)$ & $18(26.9 \%)$ & \multirow{2}{*}{$0.114^{*}$} \\
\hline & Female & $91(68.4 \%)$ & $42(63.6 \%)$ & $49(73.1 \%)$ & \\
\hline \multicolumn{2}{|c|}{ Weight(Kg) } & $65.3 \pm 15.3$ & $70.1 \pm 15.9$ & $60.7 \pm 13.3$ & $0.000 \#$ \\
\hline \multicolumn{2}{|c|}{$\mathrm{BMI}\left(\mathrm{Kg} / \mathrm{Cm}^{2}\right)$} & $25.7 \pm 6.0$ & $27.4 \pm 6.8$ & $24 \pm 4.58$ & $0.000 \#$ \\
\hline \multicolumn{2}{|c|}{ Systolic BP(Mmhg) } & $124.6 \pm 16.7$ & $134.2 \pm 16.7$ & $115.1 \pm 10.0$ & $0.000 \#$ \\
\hline \multicolumn{2}{|c|}{ Diastolic BP(Mmhg) } & $80.8 \pm 10.3$ & $86.5 \pm 9.5$ & $75.2 \pm 7.9$ & $0.000 \#$ \\
\hline \multicolumn{2}{|c|}{ Fasting Blood Glucose (Mg/DI) } & $101.2 \pm 47.2$ & $108.1 \pm 49.9$ & $94.4 \pm 43.6$ & $0.018 \#$ \\
\hline \multicolumn{2}{|c|}{ Random blood glucose (Mg/DI) } & $162.6 \pm 91.0$ & $182 \pm 99$ & $143.6 \pm 78.2$ & $0.001 \#$ \\
\hline \multicolumn{2}{|c|}{ Hba1c (\%) } & $6.4 \pm 2.1$ & $6.69 \pm 2.2$ & $6.1 \pm 2$ & $0.03 \#$ \\
\hline \multicolumn{2}{|c|}{ Total Cholesterol(Mg/DI) } & $170.4 \pm 39.0$ & $181.5 \pm 33.9$ & $159.6 \pm 40.9$ & $0.000 \#$ \\
\hline \multicolumn{2}{|c|}{ LDL(Mg/DI) } & $111.0 \pm 26.8$ & $116 \pm 25.8$ & $106.1 \pm 27.0$ & $0.000 \#$ \\
\hline \multicolumn{2}{|c|}{$\mathrm{HDL}(\mathrm{Mg} / \mathrm{DI})$} & $39.3 \pm 10.5$ & $38.2 \pm 8.24$ & $40.55 \pm 12.4$ & $0.003 \#$ \\
\hline \multicolumn{2}{|c|}{ Triglyceride(Mg/DI) } & $160.5 \pm 85.0$ & $185.4 \pm 89.5$ & $136 \pm 73.0$ & $0.067 \#$ \\
\hline \multicolumn{2}{|c|}{ Intimal Thickness $(\mathrm{Mm})$} & $0.88 \pm 0.17$ & $0.969 \pm 0.17$ & $0.80 \pm 0.13$ & $0.000 \#$ \\
\hline
\end{tabular}

Table-I. Characteristics of the population.

\begin{tabular}{|c|c|c|c|c|}
\hline Variable & $\begin{array}{c}\text { Pearson's Correlation } \\
\text { Coefficient }\end{array}$ & P-Value & $\begin{array}{c}\text { Pearson's Correlation } \\
\text { Coefficient }\end{array}$ & P-Value \\
\hline & $\begin{array}{l}\text { Hypertensive } \\
\mathrm{N}=66(49.6 \%)\end{array}$ & & $\begin{array}{c}\text { Non-hypertensive } \\
\mathrm{N}=67(50.4 \%)\end{array}$ & \\
\hline Age & 0.398 & $0.000^{\star}$ & 0.49 & $0.000 *$ \\
\hline Weight & -0.098 & 0.264 & 0.16 & 0.064 \\
\hline Bmi & -0.103 & 0.2 & 0.148 & 0.087 \\
\hline Systolic bp & 0.045 & 0.61 & 0.263 & $0.002^{*}$ \\
\hline Diastolic bp & -0.074 & 0.4 & 0.200 & $0.021^{*}$ \\
\hline Fbs & 0.392 & $0.000^{*}$ & 0.464 & $0.000^{*}$ \\
\hline Rbs & 0.371 & $0.000^{\star}$ & 0.396 & $0.000 *$ \\
\hline Hba1c & 0.427 & $0.000^{\star}$ & 0.416 & $0.000 *$ \\
\hline Total cholesterol & 0.372 & $0.000^{*}$ & 0.376 & $0.000 *$ \\
\hline Ldl & 0.296 & $0.001^{*}$ & 0.385 & $0.000 *$ \\
\hline $\mathrm{Hdl}$ & 0.146 & 0.096 & 0.027 & 0.75 \\
\hline $\mathrm{Tg}$ & 0.251 & $0.004^{\star}$ & 0.318 & $0.000 *$ \\
\hline
\end{tabular}

Table-II. Relationship of cardiometabolic risk factors with CIMT in hypertensive and non-hypertensive populations. ${ }^{*}$ Chi-square - \#Student t-test - *Significant Relationship.

CIMT was also significantly higher in hypertensive patients. The remarkable point is that the correlation coefficient for these factors showed a stronger relationship in non-hypertensive patients as compared to hypertensive patients. $\mathrm{HbA1c}$ was the only exception. This focuses our attention to the fact that blood pressure plays a more important role in development of atherosclerosis as compared to other risk factors in hypertensive patients. Although the measures of glycemic control and the different fractions of the fasting lipid profile were all higher in the hypertensive population they were more strongly related to CIMT in the subjects with normal blood pressure. These factors play an important role in the development of atherosclerosis. But hypertension overwhelms these factors and leads to a greater CIMT. Therefore an optimal control of hypertension should be the mainstay of prevention of atherosclerosis.

The prevalence of hypertension is increasing in the low and middle income countries ${ }^{8}$ and with it the complications associated with hypertension, 
especially the cardiovascular complications are also becoming more common. Hypertension contributes towards coronary, cerebral and peripheral atherosclerosis. ${ }^{9,10,11}$ The thickening of carotid intima media is an early stage of atherosclerosis. It is followed by formation of plaques and then carotid stenosis. ${ }^{12}$ Increased CIMT in hypertensive patients makes the subject susceptible to all types of cerebrovascular accidents. ${ }^{10}$ This association is especially evident with ischemic strokes. ${ }^{14}$ Increased CIMT is associated with cardiovascular disease, both coronary artery disease and cerebrovascular accidents. ${ }^{15}$ Increased CIMT>1mm is strongly related to severe coronary artery disease. ${ }^{16}$

Blood pressure plays an important role in the development of atherosclerosis. Control of blood pressure may lead to its' regression. Lowering the systolic blood pressure in type 2 diabetic patients has been documented to lead to a reduction in CIMT. ${ }^{17}$

CIMT was greater in hypertensive subjects in our study. This has been observed in a number of local and international studies. ${ }^{18,19}$ A European study showed that low insulin sensitivity, high systolic blood pressure, male gender and long term smoking was associated with a CIMT of $\geq 1.2 \mathrm{~mm} .{ }^{20}$ High blood pressure causes increased thickening of carotid wall by intimal thickening, atherosclerotic lesions and medial hypertrophy. This thickening is due to not only the high blood pressure but also the hemodynamic factors like cardiac output, heart rate, wall stress, shear stress and pulse pressure.

Intima media thickness is a strong and independent predictor of death and serious cardiovascular events in hypertensive patients with CAD. Many international studies have demonstrated the role of multiple cardiometabolic risk factors like hypertension, diabetes, dyslipidemia and smoking with increase in CIMT and its link with cardiovascular events. ${ }^{21}$ In our study we have measured CIMT in hypertensive patients and compared it with non-hypertensive patients. Incidence of hypertension increases with age. Age was strongly associated with a greater CIMT in both hypertensive and nonhypertensive subjects in our study, as was observed elsewhere. ${ }^{22}$ Systolic blood pressure especially contributed to increasing CIMT., ${ }^{5,23}$ But diastolic blood pressure was not related to a high CIMT. Some studies have shown the association of an increased pulse pressure with CIMT. ${ }^{14,24}$ Both systolic blood pressure and pulse pressure are higher in older individuals, so age along with a higher blood pressure contributes to the higher CIMT in older individuals. ${ }^{25}$ Hypertension also leads to early development of carotid plaques. ${ }^{26,27}$ Age has been found to be a major determinant of high CIMT. Many studies have shown the association of age with CIMT. CIMT increases $0.05 \mathrm{~mm}$ each year. $^{28} \mathrm{BMI}$ and physical activity also contribute to thickening of carotid wall.

In our study we also observed that when analyzed through correlation coefficient, the risk factors like the serum cholesterol, LDL and triglycerides as well as all measures of glycemic control like fasting and random blood sugars, and glycated hemoglobin were more strongly related to CIMT in non-hypertensive patients as compared to hypertensive patients. This fact supports the hypothesis that hypertension is the major contributor to CIMT as compared to other risk factors. In our study hypertensive patients showed a weaker relationship with different cardiometabolic risk factors. This could be due to the fact that hypertension itself was an independent risk factor and in hypertensive patients the total cholesterol, LDL cholesterol, fasting and random blood glucose levels and BMI were already higher than in non-hypertensive subjects. Blood pressure has been found to play a major role in the development of carotid atherosclerosis in patients with metabolic syndrome. ${ }^{29}$ While another study demonstrated that non-blood pressure component metabolic syndrome was also associated with the development of atherosclerosis in metabolic syndrome. ${ }^{30}$

It has also been demonstrated that systolic blood pressure contributes to increased CIMT even after adjusting for the confounding factors both in hypertensive and non-hypertensive subjects. ${ }^{5}$ 
The systolic and diastolic blood pressures were not significantly related to CIMT in hypertensive patients in our study, this could have been due to the fact that when subjects are actively treated for a modifiable risk factor they lose their predictive value. Management of the modifiable risk factors will modify the subjects' current status and these variables will not accurately correlate with the dependent variable. Thus CIMT measurement is very important and pertinent in such patients as it can be of assistance to evaluate the risk of cardiovascular events in these patients. ${ }^{17}$

There is considerable overlap between the different cardio-metabolic risk factors especially diabetes and hypertension. Around $50-80 \%$ of the diabetic population has been shown to be hypertensive in different populations. ${ }^{31}$ These conditions are also associated with dyslipidemia and obesity. It is important to manage these factors concurrently. According to our study hypertension is one of the most important factors that needs to be managed to control the epidemic of cardiovascular disease in the South-Asian population.

\section{CONCLUSION}

Hypertension itself thus was found to be the biggest player in the development of atherosclerosis. Adequate management of hypertension can prevent or even reverse atherosclerosis. Further studies with a larger sample size and with a study design to quantify the role of different cardiometabolic risk factors is required to further clarify the situation.

\section{Copyright(C) 11 Nov, 2019.}

\section{REFERENCES}

1. Polak J F, Pencina MJ, Pencina KM, O'Donnell C J, Wolf PA, D'Agostino R B. Carotid intima-media thickness and cardiovascular events. N Engl J Med 2011; $365: 21321$.

2. Mohan V, Ravikumar R, Shanthi-Rani S, Deepa R. Intimal medial thickness of the carotid artery in south Indian diabetic and non-diabetic subjects: The Chennai Urban Population Study (CUPS). Diabetologia 2000; 433: 494-499.
3. Khan SP, Ahmed KZ, Yaqub Z, Ghani R. Carotid intimamedia thickness: Correlation with lipid profile in patients with familial hypercholesterolemia versus controls. JCPSP 2011; 21 (1): 30-33.

4. Touboul PJ, Labreuche J, Vicaut E, et al. Carotid intima media thickness, plaques, and Framingham risk score as independent determinants of stroke risk. Stroke 2005; 36: 1741-45.

5. Ferreira J, Girerd N, Bozec E, Machu JL, Boivin JM, London GM, Zannad F, Rossignol P. Intima-Media thickness is linearly and continuously associated with systolic blood pressure in a population $\square$ based cohort (STANISLAS Cohort Study). Journal of the American Heart Association. 2016 5. e003529. 10.1161/ JAHA.116.003529.

6. Wright JT Jr, Williamson JD, Whelton PK, Snyder JK, Sink KM, Rocco MV, Reboussin DM, Rahman M, Oparil $\mathrm{S}$, Lewis CE, Kimmel PL, Johnson KC, Goff DC Jr, Fine LJ, Cutler JA, Cushman WC, Cheung AK, Ambrosius WT. A randomized trial of intensive versus standard blood pressure control. N Engl J Med 2015; 373: 2103-2116.

7. Wang $\mathrm{S}$, Wu $\mathrm{H}$, Zhang $\mathrm{Q}, \mathrm{Xu} \mathrm{J}$, Fan $\mathrm{Y}$. Impact of baseline prehypertension on cardiovascular events and all-cause mortality in the general population: A meta-analysis of prospective cohort studies. Int $\mathrm{J}$ Cardiol. 2013; 168:4857-4860.

8. Du HW, Li JY, He Y. Glycemic and blood pressure control in older patients with hypertension and diabetes: Association with carotid atherosclerosis. Journal of Geriatric Cardiology 2011; 8: 24-30.

9. Persell SD. Prevalence of resistant hypertension in the United States, 2003-2008. Hypertension 2011; 57 : 1076-80.

10. Kazemi T, Sharifzadeh GR, Zarban A, Fesharakinia A, Rezvani MR, Moezy SA. Risk factors for premature myocardial infarction: A matched case-control study. J Res Health Sci 2011; 11: 77-82.

11. Naseh G, Fard MM, Kazemi T, Mirgholami A, Hashemi $N$, Saburi A. Comparison of carotid intima-media thickness in hypertensive patients and control group. J Cardiovasc Echography 2016; 26: 48-51.

12. Zureik $M$ et al. Common carotid intima-media thickness predicts occurrence of carotid plaques: longitudinal results from the Aging Vascular Study (EVA) Study. Arterioscler Thromb Vasc Biol 2000; 20: 1622-1629. 
13. Chambless LE, Folsom AR, Clegg LX, et al. Carotid wall thickness is predictive of incident clinical stroke: The atherosclerosis risk in communities study (ARIC). AM J Epidemiol 2000; 151: 478-487.

14. O'Leary DH, Polak JF, Kronmal RA, et al. Carotid artery intima and media thickness as a risk factor for myocardial infarction and stroke in older adults. Cardiovascular health study collaborative research group. N Engl J Med 1999; 340:14-22.

15. Akosah KO, McHigh VL, Barnhart SI, Schaper AM, Mathiason MA, Perlock PA, Haider TA. Carotid ultrasound for risk clarification in young to middle-aged adults undergoing elective coronary angiography. Am J Hypertens 2006; 19: 1256-1261.

16. Howard BV, Roman MJ, Devereux RB, Fleg JL, Galloway JM, Henderson JA, et al. Effect of lower targets for blood pressure and LDL cholesterol on atherosclerosis in diabetes: The SANDS randomized trial. JAMA. 2008; 299: 1678-89.

17. Mahfouz RA, Abdou M, Elsaied A, Kandil N: Predictors of subclinical atherosclerosis and incipient myocardial dysfunction in asymptomatic young hypertensive subjects. Euro J Sci Res 2011; 49: 28-38.

18. Sorof JM, Alexandrov AV, Cardwell G, Portman RJ: Carotid artery intimal-medial thickness and left ventricular hypertrophy in children with elevated blood pressure. Pediatrics 2003; 111: 61-66.

19. Rajala U, Pa"iva"nsalo $M$, Laakso $M$, Pelkonen $O$, Suramo I, et al. Associations of blood pressure with carotid intima-media thickness in elderly Finns with diabetes mellitus or impaired glucose tolerance. J Hum Hypertens 2003; 17:705-711.

20. Zeilinski T, Dzeilinska Z, Januszewicz A, Rynkun D, Ciesla MM, Tyczynski $P$, et al. Carotid intima media thickness as a marker of cardiovascular risk in hypertensive patients with coronary artery disease. AJH 2007 October; 20(10): 1058-64.
21. Su TC, Chien KL, Jeng JS, Chen MF, Hsu HC, Torng PL, et al. Age- and gender-associated determinants of carotid intima-media thickness: A community-based study. J Atheroscler Thromb 2012; 19:872-80.

22. Rantala $A O$ et al. Hyperinsulinemia and carotid atherosclerosis in hypertensive and control subjects. Diabetes Care 1998; 21: 1188-1193.

23. Lakka TA, Salonen $R$, Kaplan GA, Salonen JT. Blood pressure and the progression of carotid atherosclerosis in middle-aged men. Hypertension 1999; 34: 51-56.

24. Kannel WB. Elevated systolic blood pressure as a cardiovascular risk factor. Am J Hypertens 2000; 85: 251-255.

25. Kallikazaros IE et al. Closed relation between carotid and ascending aortic atherosclerosis in cardiac patients. Circulation 2000; 102, III-263-III-268.

26. $\mathrm{Su} T-\mathrm{C}$ et al. Hypertension status is the major determinant of carotid atherosclerosis: A community based study in Taiwan. Stroke 2001; 32: 2265-2271.

27. Bashir F, Nageen A, Kidwai SS, Ara J. Carotid intimamedia thickness and cardiometabolic risk factors in Pakistani type 2 diabetics. Saudi J Health Sci 2017; 6:145-50.

28. Kovaite M, Petrulioniene Z, Ryliskyte L, Badariene J, Dsenkeviciute V, et al. Systemic assessment of arterial wall structure and function in metabolic syndrome. Proc West Pharmacol Soc 2007; 50: 123-30.

29. Al-Nimer MSM, Hussein II. Increased mean carotid intima media thickness in type 2 diabetes mellitus patients with non-blood pressure component metabolic syndrome: A preliminary report. Int J Diabetes Dev Ctries. 2009; 29(1):19-22.

30. Cheung BM, Li C. Diabetes and hypertension: is there a common metabolic pathway?. Current atherosclerosis reports. 2012 Apr 1;14(2):160-6.

\begin{tabular}{|c|l|l|l|}
\hline \multicolumn{3}{|c|}{ AUTHORSHIP } & AND CONTRIBUTION DECLARATION \\
\hline Sr. \# & Author(s) Full Name & \multicolumn{1}{|c|}{ Contribution to the paper } & Author(s) Signature \\
\hline 1 & Farhat Bashir & $\begin{array}{l}\text { Concept, collection of data, analysis, } \\
\text { literature review, correction. } \\
\text { Collection of data, analysis, literature } \\
\text { review, write up. } \\
\text { Collection of data, analysis, literature } \\
\text { review, write up. }\end{array}$ \\
\hline 3 & Nadia Shams & Ayesha Nageen & \\
\hline
\end{tabular}

